\section{Birlesik Dünya Arastrma Cypriot Journal of Educational \\ BD-CENTER \\ Sciences}

Innovasyon ve Yayınalık Merkezi
Volume 15, Issue 6, (2020) 1519-1534



$\underline{\text { www.cjes.eu }}$

\title{
The effect of a relaxation-based training on reducing the level of suspicious thinking among warned students
}

Fadi S. Samawi ${ }^{*}$, Associate Professor, Al- Balqa Applied University, Princess Alia University College, Department of Psychology and Special Education. Al-Salt, 19110, Jordan

\section{Suggested Citation:}

Samawi, F. (2020). The Effect of a Relaxation-based Training on Reducing the Level of Suspicious Thinking among Warned Students.Cypriot Journal of Educational Science. 15(6), 1519-1534. https://unpub.eu/ojs/index.php/cjes/article/view/5295

Received from August 20, 2020; revised from October 25, 2020; accepted from December 18, 2020.

${ }^{\circ} 2020$ Birlesik Dunya Yenilik Arastirma ve Yayincilik Merkezi. All rights reserved.

\begin{abstract}
The present study aims at measuring the effect of a relaxation-based training programme on reducing the level of suspicious thinking among warned students at Al-Balqa Applied University. To achieve the objectives of the study, a relaxation-based training programme was prepared and the Kurmash Scale was used to measure the students' level of suspicious thinking. The results indicated that the training programme had an effect on reducing the students' level of suspicious thinking, and there were statistical differences attributed to the gender variable, in favour of females, and the faculty variable, in favour of humanities faculties. This study recommends holding a series of seminars and lectures that aim at raising students' awareness about the adverse effects of suspicious thinking and how to overcome it. The significance of this study lies in identifying the important role of relaxation in reducing the level of suspicious thinking among university students, at both the academic or behavioural levels.
\end{abstract}

Keywords: Training programme, relaxation, suspicious thinking, warned students, Al-Balqa Applied University.

* AdDRess for CORReSPondence: Fadi, Samawi, Associate Professor, Al- Balqa Applied University, Princess Alia University College, Department of Psychology and Special Educatio. Al-Balqaa, 19110, Jordan

E-mail address: fadi.samawi@bau.edu.jo 


\section{Introduction}

Thinking (cognition) is God's gift to humans that distinguishes us from all other species. It has a great importance in our everyday life and in the development of societies and the formation of nations and civilisations. An individual's way of thinking depends on his/her own style, which is influenced by his/her personality, social upbringing, motivation, mental abilities, level of intelligence, educational level and other factors that shape his/her way of thinking.

Thinking is a sophisticated mental, cognitive and emotional process that is built and based on the outcomes of other psychological processes such as perception, feeling, sense of achievement and creativity, and other mental processes, such as remembering, differentiating, generalising, comparing, reasoning and analysing. Thinking plays a vital role in human life, it is our primary survival tool that helps us solve problems, avoid different types of risks, better manage and control our lives (Barakat, 2006). Parrott and Parrott (2004) argued that there are four types of thinking that range from the simplest mental processes to the most complex ones, such as transient perceptions, waking dreams, telling imaginary and fictional stories, unrealistic events that inadvertently come to mind, the belief in things that need no proof, and analytical thinking that requires analysing problems and facts before judging its validity.

University life is considered as one of the student's life stages that witnesses social, intellectual and emotional change, which may lead to facing different types of emotional and social problems. Most students encounter different types of obstacles and challenges during their university life which may lead to having a special type of thinking called suspicious thinking or doubting by which students sometimes imagine things that do not exist.

Suspicious thinking refers to a psychological origin as humans' personality has multiple internal interactions among three parts (the id, ego and superego) as stated by Freud. He also indicated that this type of thinking is caused by the conflict between the ego and the superego, causing anxiety, suspicion and mistrust (Kurmash, 2017). People with suspicious thoughts have the tendency to take other people's behaviours as an intentional negative behaviour without justification. Furthermore, suspicious thinking also refers to an indirect self-defence attempt to reach a psychological adjustment, through which the individual distorts the truth to reduce tension and anxiety resulting from his own conflicts and internal and external frustrations (Bjørkly, 2002).

Kretschmer assumed that there are two types of individuals with suspicious thoughts: the insensitive type (not showing any emotion or the so-called emotionless) and the highly sensitive type (characterised by being nervous, moody, anxious, sensitive and distrustful). Kretschmer indicated that people who have highly sensitive personalities are born with this temper (Bravi et al., 2020).

It is worth mentioning that the thinking of a suspicious personality is concerned with a constant feeling of threat, while there is no threat in reality. These suspicious thoughts can be interpreted as delusions or hallucinations in the emotional perception of a suspicious person. Suspicious personality may also exaggerate in its responses to criticism by assigning harmful meanings to other people's remarks. For example, if someone makes a negative comment about the suspicious person, he/she will think of it as a kind of hate directed towards him/ her, or that there is a hidden force that runs a smear campaign against him/her. People with suspicious personality maximise negative attitudes and fabricate imaginary thoughts. So they become the centre of a threatening and fearful universe. Accordingly, they tend to further isolate themselves from other people (Reijntjes et al., 2011). 
Jubouri (2012) stated that people cannot achieve their mission in life without having a healthy and fit body that enables them to meet their own demands. The development and complexity of societies and the speed of events occurring in human life have left people under continuous psychological pressure, which makes them more vulnerable to various types of mental or physical disorders (Jubouri, 2012).

There is a set of behaviours that characterise an individual with suspicious thoughts which includes the following: generalised mistrust of others' statements and actions, being overly cautious, anticipation, distrust and suspiciousness of others, high sensitivity, exaggeratedly affected by criticism, assigning harmful meanings to other people's remarks and being overly defensive (Waldinger, 2011).

People with suspicious thoughts are also characterised by an eccentric and illogical way of thinking, especially in two dimensions: the first is perception, where they perceive everything surrounding them as a source of threat based on their belief of conspiracy. The second is their performance and relationships with others characterised by mistrust, suspicion and misinterpretation of their comments and behaviours (Akhlaq, Asghar, Gul, Ali \& Shah, 2016).

Relaxation plays an important role in the development of greater self-control and rapid elimination of negative thoughts caused by fear, stress and anxiety. Relaxation can be used in overcoming negative thoughts and replacing them with positive thoughts that help in reducing fears and anxiety in situations that require a person to be stable and calm, such as the role of relaxation in eliminating students' pre-test anxiety. It can also be used with gradual reassuring in helping people cope with other situations that cause anxiety and tension.

Furthermore, relaxation plays a significant role in controlling people's tension levels, increasing their awareness of the sense of movement, helping them reach high levels of comfort and relief and reducing the time they need to spend to achieve a full-body relaxation. The relaxation training programme may also include the use of some positive phrases in a systematic way with the aim of weakening the power of passive thoughts and imagination (Hamidi, Saadawi \& Abdul Karim, 2004).

\subsection{Research problem and questions}

The psychological preparation process for university students can be considered as an 'economic' investment in time and effort that contributes to achieving the best results with regard to reducing students' psychological stress related to physical and functional components. The university stage is considered as one of the most important and critical stage of students' life due to its characteristics and accompanying emotional, mental, psychological and social changes.

During this stage, students face different types of pressure factors and obstacles related to both the academic side, concerning the learning process, and the behavioural side, concerning the social relationships with faculty members and other students, which may lead to having a sense of suspicion, anxiety, tension and nervous exhaustion, which weaken their ability to keep up with life and may lead to their emotional and physical exhaustion.

Relaxation is considered as one of the most important techniques of behavioural therapy that can reduce anxiety, stress, tension and worry. It is practiced in some cases as an alternative to pharmacotherapy, and as a helping technique in treating mental and physical disorders and gaining experience in controlling fears and tensions through practicing a number of relaxation skills. However, there is a significant lack of studies investigating the effect of training programmes or other educational interventions based on relaxation procedures on reducing and alleviating the levels of suspicious thinking among warned students. To the best of the researcher's knowledge, there are no 
studies in the Jordanian context, especially in the higher education context, that examine the effect of any interventional procedure on reducing the level of the suspicious thinking. The present study investigates the impact of a relaxation-based training programme on reducing the level of suspicious thinking among students at Al-Balqa Applied University. In view of the above, the current study problem is determined by answering the following questions:

First question: Are there any statistically significant differences at the $\alpha=0.05$ level between the average scores of the experimental and control groups on the scale of suspicious thinking attributed to the training programme?

Second question: Are there any statistically significant differences at the $\alpha=0.05$ level between the average scores of the experimental and control groups on the scale of suspicious thinking attributed to gender and type of faculty variables?

\subsection{Research objectives}

This study aims at identifying the effect of a relaxation-based training programme on reducing the level of suspicious thinking among warned students at Al-Balqa Applied University, clarifying the concept of both suspicious thinking and relaxation and exploring whether there are significant differences between the control and experimental groups attributed to gender and type of faculty variables.

\subsection{Research significance}

The significance of this study lies in identifying the important role of relaxation in reducing the level of suspicious thinking among university students, at both the academic or behavioural levels. The importance of the current study also lies in the problem it addresses and the scientific findings it presents through shedding light on suspicious thinking among university students who constitute an important segment of the community, and identifying the impact of a relaxation-based training programme on reducing students' level of suspicious thinking.

Moreover, this study identifies the benefits of practicing relaxation programmes by university students in drawing the attention of university professors to the vital role of these programmes in helping students achieve distinguished educational outcomes. This study also opens the door for other researchers to study the impact of relaxation-based training programmes on other variables or on different age groups and preparing scientific objective standards adapted to the Jordanian environment characterised by a high degree of validity, reliability and significance in areas of great importance to university students. The results of this study may also benefit university faculty members and staff who have direct contact with students, such as the Deanship of Student Affairs, the Admission and Registration Unit and educational decision-makers and curriculum developers.

\subsection{Conceptual and operational definitions}

Relaxation: It is a complete termination of all muscle contractions that cause tension (Sham'oun, 1999).

The operational definition of relaxation: The programme prepared for the purposes of the current study consists of eight training sessions, two sessions a week, and each session takes 60 minutes. It will last for 4 weeks.

Suspicious thinking: Bentall (2006) identified an ongoing process in the brain that does not stop or end as long as the individual is awake. People with suspicious thinking tend to interpret negative 
events in their lives by blaming others. This type of thinking arises as a result of a lack of selfconfidence and trusting others.

The operational definition of suspicious thinking: The score obtained by the members of the study sample on the scale of suspicious thinking.

Warned students: Students who commit any act of misconduct or violations listed in students' discipline by-laws of the university, who are subject to penalties that range from a written warning to the cancellation of the decision to award them a university certificate (By-laws of Al-Balqa Applied University for the year 2017). Operationally defined as students who have committed violations (academic or behavioural) and who are subject to disciplinary penalties.

\subsection{Research limitations}

\section{Research Limitations}

There are a number of limitations to this study including:

Human, spatial and temporal limitations: Students of Al- Balqa' Applied University / the Center / Warned/ Balqa Governorate / Jordan, for the first semester of the academic year 2017/2018. Objective Limitations: The impact of a relaxation-based training program on reducing the level of suspicious thinking among warned students at Al-Balqa Applied University.

The results of the study are determined by the psychometric properties of the study instruments related to its reliability and validity, and the extent of cooperation and seriousness of the study sample in answering the study questionnaire and during the program prepared for them.

\section{PREVIOUS STUDIES}

Several studies examined the variables of this study, including the study of Tellawi, Chasson and Williams (2016), which aimed at examining the relationship between hostility, suspicious thinking and obsessive-compulsive disorder severity. The study sample consisted of 161 people. The researcher used three scales to measure the research variables. The results showed that individuals with obsessive-compulsive disorder had high levels of hostility that was significantly positively associated with increased suspicious thoughts severity.

Sumich, Castro and Kumari (2014) conducted a study that aimed at identifying the level of suspicious thinking among males and females drawn from the general population. The study sample consisted of 76 females and males. The study results showed that males have a higher level of suspicious thinking compared to females. This result was attributed to confidence, irritation, impulsiveness and having negative relationships.

Bani Younis' (2005) study aimed at determining the effectiveness of a muscular relaxation technique in reducing the level of post-traumatic stress disorder among 40 male and female students at the University of Jordan. Jacobson's scales were used to evaluate the effectiveness of the muscular relaxation technique. The results showed that the muscular relaxation technique contributed to reducing the level of symptoms, and that the students in the experimental group had a continuous level of decline in these symptoms over time due to the use of this technique.

Some previous studies, such as the studies of Al-Hawari and Danoun (2009) and Bani Younes (2005), were concerned about applying relaxation training programmes and identifying their impacts or effectiveness on reducing anxiety and post-traumatic stress disorder. These studies agreed on the effectiveness of relaxation programmes on reducing various variables used in these studies, such as 
anxiety. According to the researcher's search in previous literature, it seems that there is no scientific study that has so far examined the use of a relaxation-based training programme in reducing the level of suspicious thinking among warned students, which supports the significance of the present study.

\subsection{Commenting on previous studies}

By reviewing previous studies, it is noted that some studies aimed at examining the level of suspicious thinking, while other studies investigated the relationship between suspicious thinking and some other variables, including the studies of Sumich, Castro and Kumari (2014) and the studies of Tellawi, Williams and Chasson (2016).

The current study is characterised by addressing the subject of suspicious thinking, identifying its level and applying a relaxation-based programme in reducing the level of suspicious thinking among students. It is noted that most previous studies included samples that ranged in a number of (from 40 to 190) randomly selected students, while the current study specifically addresses warned students as the sample of the study, used in identifying the type of the training programme to be used and the level of suspicious thinking. It is noted that there is a scarcity of Arab studies that examined the subject of suspicious thinking. The researcher could not find, within his search limits, any previous local study that examined the effect of applying training programmes in reducing the level of suspicious thinking, which distinguishes the current study from other studies.

\subsection{Method}

The quasi-experimental approach was used in the equivalent group method (control group, experimental group, pre-test and post-test) to determine the impact of a relaxation-based training programme on reducing the level of suspicious thinking among warned students at Al-Balqa Applied University.

\subsection{Research variables}

Independent Variable: The relaxation-based training programme.

Dependent Variable: Suspicious thinking.

Categorical Variables

Gender: Male/ Female

Type of Faculty: Scientific/ Humanities Faculties

\subsection{Participants}

The study sample consists of all (760) male and female warned students at Al-Balqa Applied University, according to the statistics of the Deanship of Student Affairs and the Admission and Registration Unit at the university, as shown in Table 1.

Table 1. Distribution of Study Population

\begin{tabular}{llll}
\hline Variable & Number of Students & N & Percentage\% \\
\hline Gender & Males & 403 & $53 \%$ \\
& Females & 357 & $47 \%$ \\
Type of Faculty & Scientific & 312 & $41 \%$ \\
& Humanities & 448 & $59 \%$ \\
Total & & 760 & $100 \%$ \\
\hline
\end{tabular}


The questionnaire was distributed to 760 male and female warned students. The number of questionnaires returned and valid for analysis was 680. After analysing the data to determine students' level of suspicious thinking, the results indicated that 145 students have above-average level of suspicious thinking. After presenting the idea of the programme to the students, 100 of them agreed to participate. They were randomly classified into 55 students representing the first group (the control group) and 45 students representing the second group (the experimental group), as shown in Table 2.

Table 2. Distribution of the study sample according to gender and faculty type

\begin{tabular}{llllll}
\hline Group & \multicolumn{2}{l}{ Gender } & \multicolumn{2}{l}{ Faculty } & Total \\
\cline { 2 - 5 } & Males & Females & Humanities & Scientific & \\
Control & 32 & 23 & 33 & 22 & 55 \\
Experimental & $\mathbf{2 4}$ & $\mathbf{2 1}$ & $\mathbf{2 5}$ & $\mathbf{2 0}$ & $\mathbf{4 5}$ \\
\hline
\end{tabular}

\subsection{Study instrument}

\subsubsection{Suspicious thinking}

This study used and modified the scale of Kurmash (2017); it consisted of 32 paragraphs and it was of self-report type; the student answers in light of a three-dimensional scale, grades were always (3), sometimes (2) and rarely (1).

Kurmash developed a scale for measuring the level of suspicious thinking among adolescent students, which was submitted (its first copy) to nine arbitrators specialised in educational and psychological sciences to verify the clarity and ability of its paragraphs to measure the level of suspicious thinking. After following the recommendations of the arbitrators, this scale was applied to 100 male and female students from outside the study sample, in order to verify its reliability and validity. The two extreme groups' method was used, the paragraphs of the scale were statistically significant at the level of 0.05 and the correlation coefficients ranged from 0.35 to 0.58 . Reliability was measured through using the test-retest method, at which it amounted to 0.91 and 0.86 , respectively.

The validity of the instrument was verified through submitting it to six faculty members and specialists in psychological and educational sciences in Jordanian universities; they were asked to express their opinion on the construction and clarity of paragraphs, the validity of each paragraph in measuring what it was supposed to measure and the accuracy and proper use of language.

They were also asked to make changes to the wordings of the paragraph and to delete or add to paragraphs. Based on their observations, four paragraphs were modified due to their wordings. Signs of internal validity were identified. The correlation coefficients between the paragraphs and the total score on the scale of the study were identified in a survey sample that consisted of 35 male and female students from outside the study sample, as shown in Table 3. 
Table 3. Correlation coefficients between the paragraphs and the total score on the study scale

\begin{tabular}{|c|c|c|c|c|c|c|c|}
\hline $\begin{array}{l}\text { Paragraph } \\
\text { Num. }\end{array}$ & $\begin{array}{l}\text { correlation } \\
\text { coefficients } \\
\text { with the } \\
\text { instrument }\end{array}$ & $\begin{array}{l}\text { Paragraph } \\
\text { Num. }\end{array}$ & $\begin{array}{l}\text { correlation } \\
\text { coefficients } \\
\text { with the } \\
\text { instrument }\end{array}$ & $\begin{array}{l}\text { Paragraph } \\
\text { Num. }\end{array}$ & $\begin{array}{l}\text { correlation } \\
\text { coefficients } \\
\text { with the } \\
\text { instrument }\end{array}$ & $\begin{array}{l}\text { Paragraph } \\
\text { Num. }\end{array}$ & $\begin{array}{l}\text { correlation } \\
\text { coefficients } \\
\text { with the } \\
\text { instrument }\end{array}$ \\
\hline 1 & $0.734^{*}$ & 9 & $.526 * *$ & 17 & $.556^{* *}$ & 25 & $0.700 *$ \\
\hline 2 & $.370^{*}$ & 10 & $.410^{*}$ & 18 & $.430 *$ & 26 & $.382 *$ \\
\hline 3 & $.418^{*}$ & 11 & $.380 *$ & 19 & $.390 *$ & 27 & $.448 *$ \\
\hline 4 & $.620 * *$ & 12 & $.533^{* *}$ & 20 & $.535^{* *}$ & 28 & $.600 * *$ \\
\hline 5 & $.533^{* *}$ & 13 & $.612^{* *}$ & 21 & $.632^{* *}$ & 29 & $.523 * *$ \\
\hline 6 & $.521^{* *}$ & 14 & $.530 * *$ & 22 & $.550 * *$ & 30 & $.571 * *$ \\
\hline 7 & $.630 * *$ & 15 & $.505^{* *}$ & 23 & $.525^{* *}$ & 31 & $.630 * *$ \\
\hline 8 & $.421 *$ & 16 & $0.584 * *$ & 24 & $0.585^{* *}$ & 32 & $.451 *$ \\
\hline
\end{tabular}

*Statistical significance at the level of significance $(\alpha=0.05)$. **Statistical significance at the level of significance $(\alpha=0.01)$.

It is noted from Table 3 that the correlation coefficients ranged from 0.37 to 0.734 , which are suitable for study purposes.

\subsubsection{Reliability}

In order to test the reliability of the suspicious thinking scale, the scale was applied to a sample of 35 students from the original study population and from outside the study sample. The coefficient of reliability was measured using Cronbach's alpha, and it was 0.841 . This value is acceptable for the purposes of the present study. The coefficient of reliability was also measured on the previous reliability sample using the application and reapplication method with a time lag of 2 weeks using Pearson's correlation coefficient as shown in Table 4.

Table 4. Pearson's correlation coefficient between the application and re-application on suspicious thinking scale

\begin{tabular}{llllll}
\hline Tests & Groups & Mean & $\begin{array}{l}\text { Standard } \\
\text { Deviation }\end{array}$ & $\begin{array}{l}\text { Correlation } \\
\text { Coefficient }\end{array}$ & $\begin{array}{l}\text { Significance } \\
\text { Level }\end{array}$ \\
\hline $\begin{array}{l}\text { Suspicious } \\
\text { Thinking }\end{array}$ & Application & 3.2547 & .38064 & $.901^{* *}$ & .000 \\
\hline
\end{tabular}


* Statistical significance at the level of significance $(\alpha=0.05) * *$ Statistical significance at the level of significance $(\alpha=0.01)$.

Table 4 shows that there is a statistically significant correlation at the level of significance $(\alpha=0.01)$ between the application and re-application on the suspicious thinking scale, which is evidence of its reliability.

To verify that the research groups are equivalent in the pre-measurement and to confirm that the improvement in the study variables is attributed to the programme, the measurement on the suspicious thinking scale was applied to the two groups of the study sample before applying the programme, and the Independent sample $t$-test was conducted to identify the statistical significant differences between the two groups in the pre-measurement, as shown in Table 5.

Table 5. Independent sample t-test to examine the differences between the members of the experimental group $(n=45)$ and the control group $(n=50)$ in the pre-measurement of suspicious thinking

\begin{tabular}{llllll}
\hline & Groups & Mean & $\begin{array}{l}\text { Standard } \\
\text { Deviation }\end{array}$ & T- Value & $\begin{array}{l}\text { Significance } \\
\text { Level }\end{array}$ \\
\hline $\begin{array}{l}\text { Suspicious } \\
\text { Thinking }\end{array}$ & Experimental & 3.4353 & .41339 & .580 & .564 \\
& Control & 3.3727 & .42360 & & \\
\hline
\end{tabular}

*Statistical significance at the level of significance $(\alpha=0.05)$.

Table 5 shows that there are no statistically significant differences between the control and experimental groups according to suspicious thinking scale, which is evidence that the two groups are equivalent in these variables before starting the programme.

\subsection{Second: the training programme}

\subsubsection{Programme description}

The relaxation-based training programme includes a variety of skills and sessions based on the selective theory, in which the researcher presents sessions within a specified period of time in order to help students reduce their level of suspicious thinking. The programme consists of eight training sessions that lasts for 4 consecutive weeks, two sessions a week, each session takes 60 minutes, in a fully equipped training centre at the university. The training was presented using various training methods, such as dialogue, discussion, relaxation, problem-solving skills, stress management training, giving examples related to session subject and carrying out various types of activities through role playing and working in groups. The main objectives of the programme are:

- Training students on how to manage and control their emotions to achieve emotional balance and psychological and social adaptation.

- Identifying negative thinking that causes suspicion and encouraging students to think positively.

- Helping students develop some skills to overcome negative behaviours, such as suspicion.

- Demonstrating students' potentials in various types of activities. 
- Providing students with a number of role models which encourages their desired positive behaviour and attitude.

\subsubsection{Programme validity}

To figure out the effectiveness of the training programme prepared by the researcher on reducing the level of suspicious thinking among students and reviewing its activities and exercises that achieve its objectives, as well as determining the implications of content's validity in light of the characteristics of the study sample, the programme was submitted to six faculty members and arbitrators specialised in psychological and educational sciences in AL-Balqa Applied University and other Jordanian universities who recommended the following: correcting some linguistic errors, increasing the number of the training programme sessions, using diverse counselling techniques that fit the subject of suspicious thinking and increasing the number of activities in the programme. After adjusting the training programme by following the arbitrators' recommendations, amendments and opinions, the final programme was prepared, as shown in Figure 1.

Figure 1. The relaxation training programme

\begin{tabular}{|c|c|c|c|c|}
\hline $\begin{array}{l}\text { Session } \\
\text { Number }\end{array}$ & Session Topic & Session Objective & Strategies & Time \\
\hline First session & Introduction & $\begin{array}{l}\text { Introducing the participants } \\
\text { to each other. } \\
\text { An orientation about the } \\
\text { programme, its objectives } \\
\text { and what can be achieved } \\
\text { through it. In addition to } \\
\text { clarifying and discussing the } \\
\text { concept of relaxation, } \\
\text { suspicious thinking and } \\
\text { homework. }\end{array}$ & Discussion and Debate & 60 minutes \\
\hline Second session & $\begin{array}{l}\text { Suspicious } \\
\text { Thinking, } \\
\text { definition, } \\
\text { causes and } \\
\text { adverse effects }\end{array}$ & $\begin{array}{l}\text { Identifying the definition of } \\
\text { suspicious thinking and its } \\
\text { adverse psychological, } \\
\text { physical, social and mental } \\
\text { effects. }\end{array}$ & $\begin{array}{l}\text { Explanation } \quad \text { and } \\
\text { clarification, debate and } \\
\text { discussion, role-playing } \\
\text { and modelling. }\end{array}$ & 60 minutes \\
\hline Third session & $\begin{array}{l}\text { Stress and } \\
\text { suspicion } \\
\text { management } \\
\text { training }\end{array}$ & $\begin{array}{l}\text { Talking about the different } \\
\text { types of suspicion and } \\
\text { tensions that the group } \\
\text { members face in their lives }\end{array}$ & $\begin{array}{l}\text { Explanation, clarification, } \\
\text { dialogue, discussion and } \\
\text { emphasis on the principle } \\
\text { of absolute openness in } \\
\text { conversations and giving } \\
\text { some examples of } \\
\text { activities that reduce the } \\
\text { level of suspicious thinking } \\
\text { as giving positive feedback } \\
\text { to students' responses to } \\
\text { existing behaviour and } \\
\text { converting their } \\
\text { pessimistic thoughts and } \\
\text { feelings into a more } \\
\text { optimistic one. }\end{array}$ & 60 minutes \\
\hline Fourth session & Stage Acting & $\begin{array}{l}\text { Helping students express } \\
\text { their thoughts and feelings }\end{array}$ & $\begin{array}{l}\text { Theatre performance, } \\
\text { explanation, clarification, }\end{array}$ & 60 minutes \\
\hline
\end{tabular}




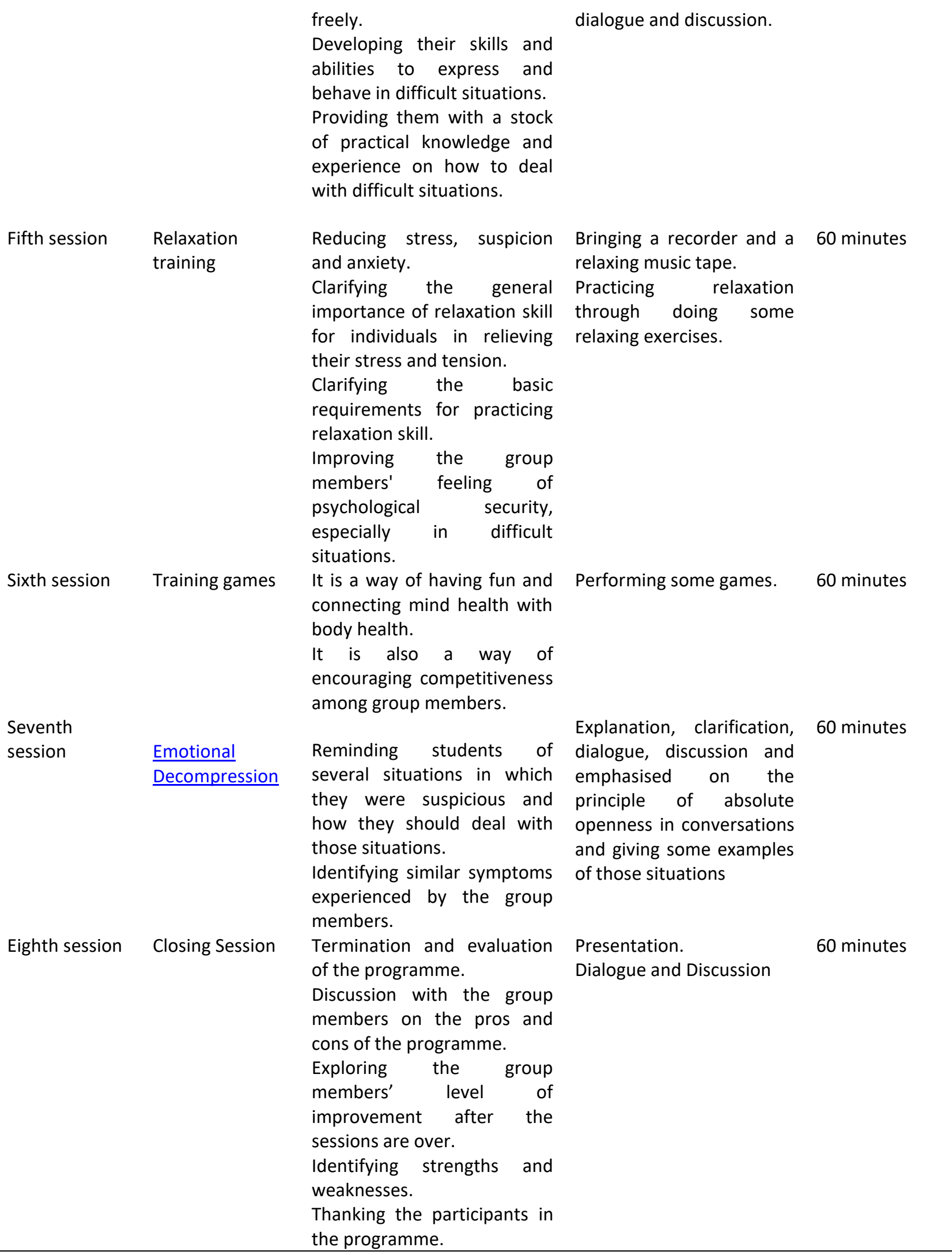




\subsection{Research procedures}

- The validity and reliability of the list of the suspicious thinking scale were verified, and the training programme was prepared after referring to the theoretical literature in this field.

- Official approvals from Al-Balqa Applied University were obtained to facilitate the researcher's task during the application of the study instruments.

- Identifying the members of the study sample in coordination with the Admission and Registration Unit and the Deanship of Student Affairs. In order to facilitate the implementation of the programme, the training programme sessions were held in one of the university equipped halls for 4 consecutive weeks with two sessions a week. The programme was applied to the students in the experimental group who were randomly selected after identifying the students who obtained the highest scores in the scales of suspicious thinking in the pre-application phase.

- A post-measurement was applied to the suspicious thinking scale at the end of the programme for both the control and experimental groups to examine the impact of the relaxation-based training programme on reducing students' symptoms of suspicious thinking.

- Data were then entered into the computer to extract results using the Statistical Package for Social Sciences (SPSS).

\section{Results}

First question: Are there any statistically significant differences at $\alpha=0.05$ level between the average scores of the experimental and control groups on the suspicious thinking scale attributed to the training programme?

To answer this question, the means, standard deviations and modified means of warned students on the scale of suspicious thinking were measured according to the groups' variables (experimental and control), as illustrated in Table 6.

Table 6. The means, standard deviations and modified means of the scores of warned students on the suspicious thinking scale according to the group variable

\begin{tabular}{|c|c|c|c|c|c|c|c|c|}
\hline & \multirow[t]{2}{*}{ Group } & \multicolumn{2}{|l|}{ Pre } & \multicolumn{2}{|l|}{ Post } & \multirow[t]{2}{*}{ Mean } & \multirow{2}{*}{$\begin{array}{l}\text { Standar } \\
\text { d error }\end{array}$} & \multirow{2}{*}{$\begin{array}{l}\text { Numbe } \\
r\end{array}$} \\
\hline & & Mean & $\begin{array}{l}\text { Standard } \\
\text { deviation }\end{array}$ & Mean & $\begin{array}{l}\text { Standard } \\
\text { deviation }\end{array}$ & & & \\
\hline $\begin{array}{l}\text { Suspiciou } \\
\text { s thinking }\end{array}$ & $\begin{array}{l}\text { experiment } \\
\text { al }\end{array}$ & 2.88 & 0.296 & 2.21 & 0.145 & 2.205 & 0.032 & 45 \\
\hline $\begin{array}{ll}\text { as } & \text { a } \\
\text { whole } & \end{array}$ & control & 2.93 & 0.163 & 2.88 & 0.194 & 2.877 & 0.032 & 55 \\
\hline & Total & 2.91 & 0.238 & 2.54 & 0.378 & 2.541 & 0.022 & 100 \\
\hline
\end{tabular}

Table 6 shows an apparent variance in the means, standard deviations and modified means of the warned students' scores on the scale of suspicious thinking as a whole due to the difference in the group variable (experimental and control). To illustrate the significance of the statistical differences found between the means, the one-way analysis of covariance (ANCOVA) was used, as illustrated in Table 7. 
Table 7. The one-way analysis of covariance (ANCOVA) of the effect of group variable on suspicious thinking scale as a whole



As for suspicious thinking as a whole, Table 7 shows statistically significant differences at the $\alpha=0.05$ level attributed to the effect of the group variable with a value of 225.605 and a statistical significance of 0.000 . These differences are in favour of the training programme.

In order to determine the effectiveness of the relaxation-based training programme in reducing the level of warned students' suspicious thinking, the effect size measurement ETA-square $\left(\eta^{2}\right)$ was found to be 0.798 . This means that $79.8 \%$ of the variance in the scores of warned students' suspicious thinking is attributed to the training programme, while the remaining variance is attributed to other uncontrolled factors.

Second question: Are there any statistically significant differences at the $\alpha=0.05$ level between the average scores of the experimental and control groups on the scale of suspicious thinking attributed to gender and type of faculty variables.

To answer this question, the means and standard deviations of warned students' scores were measured on the scale of suspicious thinking according to the gender variable. To illustrate the statistical differences between the means, the $t$-test was used, as shown in Table 8.

Table 8. Means, standard deviations and $t$-test according to the scores of warned students on the scale of suspicious thinking according to gender variable

\begin{tabular}{|c|c|c|c|c|c|c|c|}
\hline & Gender & Number & Mean & $\begin{array}{l}\text { Standard } \\
\text { Deviation }\end{array}$ & "T" Value & $\begin{array}{l}\text { Degrees } \\
\text { of } \\
\text { Freedom }\end{array}$ & $\begin{array}{l}\text { Significance } \\
\text { Level }\end{array}$ \\
\hline \multirow{2}{*}{$\begin{array}{l}\text { Suspicious } \\
\text { Thinking } \\
\text { as a whole }\end{array}$} & Male & 21 & 2.48 & .373 & -2.055 & 98 & .044 \\
\hline & Female & 24 & 2.69 & .354 & & & \\
\hline
\end{tabular}

Table 8 shows that there are statistically significant differences at the $\alpha=0.05$ level attributed to gender variable in the scale of suspicious thinking; the differences are in favour of females.

The means and standard deviations of the scores of the warned student on the scale of suspicious thinking were measured according to faculty variable. To illustrate the statistical differences between the means, the $t$-test was used, as shown in Table 9. 
Table 9. Means, standard deviations and $t$-test according to faculty variable scores of warned students on the scale of suspicious thinking

\begin{tabular}{llllllll}
\hline & Faculty & Number & Mean & $\begin{array}{l}\text { Standard } \\
\text { Deviation }\end{array}$ & $\begin{array}{l}\text { "T" } \\
\text { Value }\end{array}$ & $\begin{array}{l}\text { Degrees } \\
\text { of } \\
\text { Freedom }\end{array}$ & $\begin{array}{l}\text { Significanc } \\
\text { e Level }\end{array}$ \\
\hline $\begin{array}{l}\text { suspicious } \\
\text { thinking }\end{array}$ & Scientific & 20 & 2.48 & .351 & -2.383 & 98 & .020 \\
$\begin{array}{l}\text { as a whole } \\
\text { Humanities }\end{array}$ & 25 & 2.73 & .400 & & & \\
\hline
\end{tabular}

Table 9 shows statistically significant differences at the $\alpha=0.05$ level due to the faculty variable on the suspicious thinking scale; these differences are in favour of humanities faculties.

\section{Discussion}

The researcher believes that the programme employs various strategies that include different types of skills, such as explaining, clarifying, dialogue, discussion, emphasising the principle of absolute openness in conversations and giving some examples of the activities that contribute to reducing the level of students' suspicious thinking as giving positive feedback to students' responses to the existing behaviour, and turning their pessimistic thoughts and feelings into more optimistic ones.

The programme also helps students express their thoughts and feelings freely, develops their skills and abilities to express and behave in difficult situations, provides them with a stock of knowledge and practical experience on how to deal with difficult situations, reduces their tension, suspicion and anxiety and shows the importance and benefits of the relaxation skills in helping people get rid of their tensions and pressures.

It also identifies the basic factors influencing the effect of relaxation. Furthermore, it improves students' feeling of psychological security, especially in difficult situations. The importance of relaxation lies in being one of the psychological experimental variables that helps individuals reduces their muscle tension, control their anger, cope with stress and manage different types of tension. Therefore, it is more important and necessary for people suffering from chronic anxiety and tension (Pagnini, Manzoni, Castelnuovo \& Molinari, 2013).

This result is partially consistent with the studies of Al-Hawari and Danoun (2009) and Bani Younis (2005), who agreed on its important role in reducing anxiety and trauma.

In addition, the results showed that that there are statistically significant differences at the $\alpha=$ 0.05 level attributed to gender variable on the scale of suspicious thinking; the differences are in favour of females. The researcher believes that this result is logical and it conforms to the result of the previous question, considering the important role of the programme in developing students' skills and abilities to express and behave in difficult situations, providing them with a stock of knowledge and practical experience in dealing with difficult situations and reducing students' tension, suspicion and anxiety. This is consistent with the gender perspective prevalent in our society that is characterised by male domination, manifested in the programme during the practical psychological comfort sessions of females.

Furthermore, there were statistically significant differences at the $\alpha=0.05$ level due to the faculty variable on the suspicious thinking scale; these differences are in favour of humanities 
faculties. The researcher believes that this result is consistent with the nature of the courses of humanities faculties and the knowledge interests of its students and the programme's compatibility with the nature of these courses.

\section{Conclusion}

The study concludes that the training programme had an effect on reducing students' level of suspicious thinking, and there were statistical differences attributed to the gender variable, in favour of females, and to the faculty variable, in favour of humanities faculties.

\section{Recommendations}

The study recommends that there is a need for paying more attention to warned students to help them boost their self-confidence and their ability to trust others, which in turn contributes to reducing their level of suspicious thinking. In addition, the study recommends holding a series of seminars and lectures that aim at raising students' awareness about the negative effects of suspicious thinking and how to overcome it. Furthermore, it recommends adopting the approach of relaxation in the psychological preparation of warned students for its positive effects on their psychological emotions and studying the impact of the relaxation-based programme on other psychological variables such as anxiety and tension.

\section{Conflict of interest}

The author declares that there is no conflict of interest.

\section{References}

Akhlaq, N., Asghar, U., Gul, T., Ali, S. Y. \& Shah, N. (2016). Evaluate personality disorders symptoms in different individuals. Annals of Psychophysiology. Retrieved from http://aeirc-edu.com/wpcontent/uploads/Download-full-Paper-13a.pdf

Al-Hawari, O. \& Danoun, T. (2010). The effect of progressive relaxation program on test anxiety and practical achievement in Gymnastic Course, Al-Rafidain Journal for Sport Sciences, 16(53), 186-209.

Bani Younis, M. (2005). Effectiveness of a muscle relaxation technique on reducing levels of Posttraumatic Stress Disorder symptoms among undergraduate students at the University of Jordan. Dirasat: Human and Social Sciences, 32(3), 581-595. Retrieved from http://journals.ju.edu.jo/DirasatHum/article/view/1484/1474

Barakat, Z. (2006). The positive and negative thinking: field study on university students among some variables. (PhD). Al - Quds Open University, Palestine, Department of Psychology, Education Psychology.

Bentall, R. P. \& Taylor, J. L. (2006). Psychological processes and paranoia: implications for forensic behavioral science. Behavioral Sciences and the Law, 24(3), 277-294. doi:10.1002/bsl.718

Bjørkly, S. (2002). Psychotic symptoms and violence toward others - a literature review of some preliminary findings. Aggression and Violent Behavior, 7(6), 605-615. doi:10.1016/s1359-1789(01)00050-7

Bravi, C. A., Fossati, N., Gandaglia, G., Suardi, N., Mazzone, E., Robesti, D., Osmonov, D., ... Briganti, A. (2020). Long-term outcomes of salvage lymph node dissection for nodal recurrence of prostate cancer after radical prostatectomy: not as good as previously thought. European Urology, 78(5), 661-669. doi:10.1016/i.eururo.2020.06.043

Hamidi, M., Alsaadawi, M. \& Abdul Karim, S. (2004). The effects of (self and imaginary) relaxation exercises on the emotional arousal and some Kinematic changes from starting to cross the first hurdle in $110 \mathrm{~m}$ hurdles race. Journal of Physical Education Sciences, 2(5), 21. Retrieved from http://www.uobabylon.edu.iq/publications/sports edition8/physical journal8 7.doc 
Jubouri, Z. (2012). The effect of a proposed relaxation program for weight loss on limiting or reducing anxiety among overweight or obese females. Al.Qadisiya Journal for the Sciences of Physical Education, 12(1), 35-54. Retrieved from https://www.iasj.net/iasj?func=fulltext\&ald=46794

Kurmash, H. (2017). Suspicious thinking among adolescent students in middle school. International Journal of Educational and Psychological Studies, 2(2), 197-217. Retrieved from http://search.shamaa.org/PDF/Articles/JOljeps/ljepsVol2No2Y2017/ijeps 2017-v2-n2 197-217.pdf

Pagnini, F., Manzoni, G. M., Castelnuovo, G. \& Molinari, E. (2013). A brief literature review about relaxation therapy and anxiety. Body, Movement and Dance in Psychotherapy, 8(2), 71-81. doi:10.1080/17432979.2012.750248

Parrott, L. \& Parrott, L. (2004). The power of negative thinking. Retrieved 22, 2019, from http://www.cross Walk.com/family/1206128.html.

Reijntjes, A., Thomaes, S., Kamphuis, J. H., Bushman, B. J., de Castro, B. O. \& Telch, M. J. (2011). Explaining the paradoxical rejection-aggression link: the mediating effects of hostile intent attributions, anger, and decreases in state self-esteem on peer rejection-induced aggression in youth. Personality and Social Psychology Bulletin, 37(7), 955-963. doi:10.1177/0146167211410247

Sham'oun, M. (1999). Sport psychology and psychometrics. Cairo, Egypt: Book Center for Publishing.

Sumich, A., Castro, A. \& Kumari, V. (2014). N100 and N200, but not P300, amplitudes predict paranoia/suspiciousness in the general population. Personality and Individual Differences, 61-62, 7479. doi:10.1016/j.paid.2014.01.009

Tellawi, G., Williams, M. T. \& Chasson, G. S. (2016). Interpersonal hostility and suspicious thinking in obsessivecompulsive disorder. Psychiatry Research, 243, 295-302. doi:10.1016/j.psychres.2016.06.038

Waldinger, T. (2011). Cognitive therapy. New Jersey: Fress Publishers Ltd. 